\title{
DETERMINAÇÃO DE Cd, Cr E AI EM TECIDO DE PEIXES PROVENIENTES DO RIO GELADO/APA, FLORESTA DE CARAJÁS-PA
}

\section{Cd, Cr AND AI DETERMINATION IN FISH TISSUE FROM GELADO RIVER/APA, CARAJÁS-PA FOREST}

\section{Bruno de Cássio Veloso Barros ${ }^{1}$, Simone de Fátima Pinheiro ${ }^{2}$ Pereira, Dulcidéia da Conceição Palheta ${ }^{3}$, Cléber Silva e Silva ${ }^{2}$}

${ }^{1}$ Universidade Federal do Pará, Instituto de Ciências da Saúde- Faculdade de Nutrição, UFPA - Av. Generalíssimo Deodoro, s.n, Cep: 66.050-060. e-mail: brunocvb@yahoo.com.br;

${ }^{2}$ Programa de Pós-Graduação em Química - Laboratório de Química Analítica e Ambiental (LAQUANAM) da Universidade Federal do Pará. Av. Augusto Corrêa ${ }^{\circ}$

1, Campus Universitário do Guamá, Belém, Cep: 66075-900, Brasil. e-mail: simonefp@ufpa.br; clebsilva1@yahoo.com.br

${ }^{3}$ Laboratório de Análise de Minerais-ISPA-UFRA; Av. Presidente Tancredo Neves, no 2501 Bairro: Montese, Cep: 66.077-901 Cidade: Belém-Pará-Brasil. e-mail: deiapalheta@hotmail.com

\section{RESUMO}

Os peixes existentes no rio Gelado estão submetidos ao aporte de metais pesados, oriundos de rejeitos de uma das maiores mineradoras do mundo, que utiliza o rio como receptáculo de água de lavagem de minério. $\mathrm{O}$ trabalho teve como objetivo avaliar a presença de $\mathrm{Cd}, \mathrm{Cr}$ e $\mathrm{Al}$ no tecido de peixes das espécies: piranha (Serrasalmus spp.), branquinha (Potamorhina spp.) e tucunaré (Cichla spp.) coletadas no rio Gelado, tendo em vista a preservação da saúde da população que consome estas espécies. As amostras foram solubilizadas usando abertura úmida e forno de microondas, e os metais analisados através do ICPAES (espectrometria de emissão atômica com plasma indutivamente acoplado). $\mathrm{Al}, \mathrm{Cd}$ e $\mathrm{Cr}$ foram encontrados em altas concentrações, em todas as espécies avaliadas, representando um grande risco à saúde pública. Os elementos $\mathrm{Al}$ e $\mathrm{Cr}$ apresentaram excelentes correlações na espécie piranha. As análises estatísticas demonstram a influência da ação antrópica na região, levando a necessidade de futuros estudos para a verificação da dinâmica de correlação com outros elementos traços. As análises mostram que os elementos estão sendo absorvidos pelos peixes, e que os níveis de concentração de alguns elementos podem causar danos à saúde da população consumidora destas espécies. 
Palavras-chave: Ictiofauna. Metais pesados. Amazônia. Área de proteção ambiental. Mineração.

\begin{abstract}
The fish on the Gelado River are subject to the contamination of heavy metals derived from waste one of the largest mining companies in the world, which uses the river as receptacle of water for washing ore. The study objective was to evaluate the $\mathrm{Cd}, \mathrm{Cr}$ and $\mathrm{Al}$ presence in tissue samples of fish species: piranha (Serrasalmus spp.), branquinha (Potamorhina spp.) and tucunaré (Cichla spp.) collected in the Gelado River, a view to preserve the population health that consumes these species. The samples were dissolved using wet opening and microwave, and metals analyzed by ICPAES (inductively coupled plasma atomic emission spectroscopy). $\mathrm{Al}, \mathrm{Cd}$ and $\mathrm{Cr}$ were found in high concentrations in all evaluated species, representing a major risk to public health. The elements $\mathrm{Al}$ and $\mathrm{Cr}$ presented excellent correlation in piranha species. Statistical analysis revealed the influence of anthropogenic activity in the region, leading to the need for future studies to verify the dynamics of correlation with other trace elements. The analysis shows that the elements are being absorbed by fish and the concentrations of some elements can damage the health of consumers of these species.
\end{abstract}

Keywords: Ichthyofauna. Heavy metals. Amazon. Environmental protection area. Mining.

\title{
1. INTRODUÇÃO
}

A Amazônia corresponde a uma das maiores regiões da Terra, com potencialidade para a descoberta de bens minerais. Apesar das limitações ainda existentes ao conhecimento do seu subsolo, as últimas décadas revelaram uma considerável variedade de ambientes geológicos, com potencialidade para depósitos minerais (BECKER e MACHADO, 1982). A implantação e a operação de uma mineração de ferro a céu aberto acarretam modificações no meio ambiente, afetando, substancialmente, as estruturas relacionadas ao meio físico e biótico.

A Companhia Vale do Rio Doce (CVRD) é considerada uma das maiores mineradoras do mundo e exploram na Serra dos Carajás, minérios de ferro, manganês e outros (CARRINO et al., 2008). A Resolução 242/2005 da Agência Nacional de Águas outorgou à CVRD o direito de uso dos recursos hídricos da Área de Proteção Ambiental (APA) do Rio Gelado por 20 anos, com a finalidade de construir diques e barragens para a contenção de minério de baixa granulometria e sedimentos advindos das minas de ferro de Carajás. A APA do Rio Gelado foi criada pelo IBAMA com a finalidade de preservar o entorno de área de exploração mineral localizada na Serra dos Carajás no estado do Pará. A utilização dos recursos hídricos da APA, principalmente o uso do igarapé Gelado, com a finalidade de mineração levantou a 
possibilidade de estar havendo poluição naquelas águas e nos peixes presentes na cadeia trófica.

A mineração adiciona ao ambiente, elementos tóxicos que normalmente, estão imobilizados no minério e que por intemperismo, processos químicos e biológicos, se tornam disponíveis levando à contaminação de ecossistemas, favorecendo o acúmulo destes elementos na biota aquática podendo chegar ao homem (BAIRD, 1999). A principal via de intoxicação de seres humanos por poluentes inorgânicos, associados a sistemas aquáticos, é o consumo de pescado contaminado (MACKAY e CLARK, 1991).

A avaliação dos níveis de metais pesados em peixes consumidos localmente é o primeiro passo para a avaliação de riscos à população humana devido à contaminação ambiental por esses metais (NIENCHESKI et al., 2001). Tanto elementos essenciais quanto não essenciais são tóxicos aos organismos vivos, quando presentes em altas concentrações. Muitos metais pesados podem ser acumulados no organismo aquático até níveis que podem ser prejudiciais às pessoas que os consomem (GOLDBERG et al., 1983). A presença de metais pesados em peixes e outros alimentos estão associados a riscos em relação à saúde pública porque estes contaminantes podem acumular-se nos homens se estes organismos forem consumidos (JONES et al., 2000).

Os riscos a saúde associados à ingestão de pescado contaminado chegam a ser de vinte a quarenta vezes mais elevada do que o resultado de ingestão de água contaminada. Isto se deve ao fato dos organismos aquáticos serem capazes de concentrar os elementos traço em até cento e cinco vezes as concentrações observadas no meio ambiente (FORAN, 1990).

Um dos modos de medir a saúde ecológica é através da busca de organismos que possam ser bons bioindicadores de contaminação (BURGER e COCHFELD, 2001). Os recursos hídricos são o habitat natural de uma infinidade de espécies de peixes que podem ser usados como bioindicadores de contaminação ambiental (STEIN et al., 1992; TRIEBSKORN et al., 2008).

Os metais pesados, quando em excesso, são tóxicos e podem causar danos ao organismo humano, principalmente alterações no sistema nervoso central (MEADOR et al., 2005). Metais como o $\mathrm{Al}, \mathrm{Fe}, \mathrm{Cu}, \mathrm{Zn}$ e $\mathrm{Mn}$ são essenciais no metabolismo biológico, enquanto que $\mathrm{Hg}, \mathrm{Pb}, \mathrm{Cr}$ e $\mathrm{Cd}$ não são essenciais e, portanto, são tóxicos, mesmo em níveis traço (AVEGLIANO et al., 2008). Os metais essenciais podem também produzir efeitos tóxicos quando em concentrações elevadas (TÜZEN, 2003). Organismos que habitam áreas contaminadas são geralmente expostos a elevadas concentrações destes elementos, ou em formas químicas distintas daquelas normalmente presentes em um ecossistema não perturbado (WOO et al., 1995; LEWIS et al., 2002). Os metais pesados podem afetar a capacidade natatória dos peixes, aumentado os movimentos de atração ou fuga, alterando a percepção sensorial e reduzindo as respostas olfativas associados à alimentação, acasalamento e a orientação (ATCHISON et al., 1987). 
O objetivo deste trabalho foi avaliar a presença de $\mathrm{Cd}, \mathrm{Cr}$ e $\mathrm{Al}$ no tecido de peixes das espécies: piranha (Serrasalmus spp.), branquinha (Potamorhina spp.) e tucunaré (Cichla spp.) coletadas no igarapé Gelado- Serra dos Carajás-PA, tendo em vista a necessidade de constante monitoramento em alimentos visando à proteção à saúde da população que consome estas espécies.

\section{METODOLOGIA}

A Área de Preservação Ambiental Rio Gelado localiza-se na Serra dos Carajás no estado do Pará, entre as latitudes $06^{\circ} 00^{\prime} 10 \mathrm{~S}$ e $05^{\circ} 52^{\prime} 20 \mathrm{~S}$ e longitudes $50^{\circ} 28^{\prime} 78^{\prime \prime} \mathrm{W}$ e $49^{\circ} 57^{\prime} 30^{\prime \prime} \mathrm{W}$ (Figura 1).

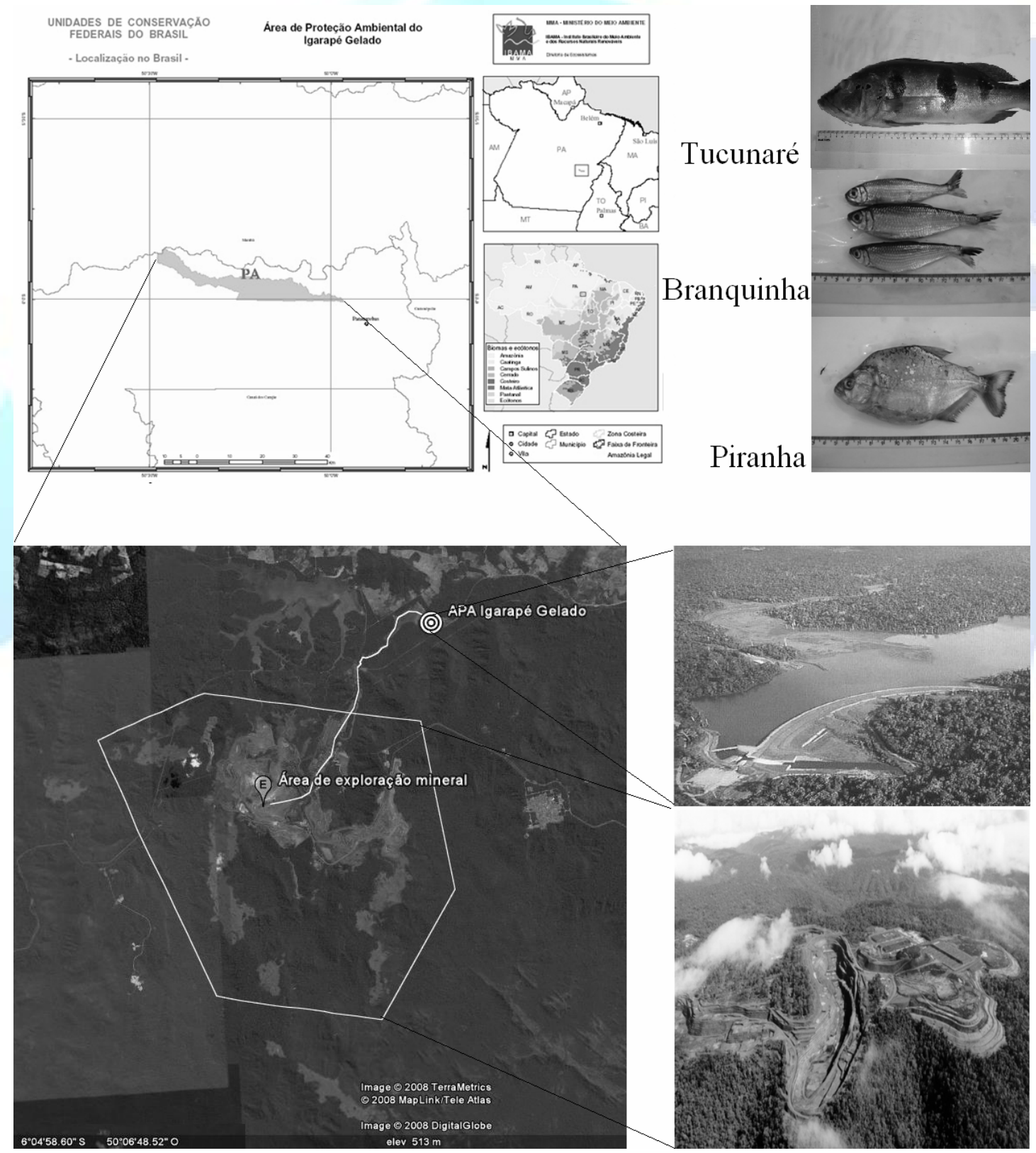

Figura 1. APA - Área de Proteção Ambiental do rio Gelado Fonte: Google Earth, IBAMA e Companhia Vale 
A APA foi criada pelo Decreto $\mathrm{n}^{\circ} 97.718$ de cinco de maio de 1989 da Presidência da República. No decreto de criação ficou estabelecido que o IBAMA fosse o responsável pela indicação das atividades a serem desenvolvidas na área.

A Serra dos Carajás localiza-se entre os rios Itacaiúnas e Parauapebas, caracteriza-se por uma série de serras descontínuas e morros, afastados por extensos vales. As principais elevações são a Serra Norte e Serra Sul. A Serra dos Carajás constitui-se de vários morros de minérios de ferro, emergentes acima da planura florestada com elevações de 600 a $800 \mathrm{~m}$. Escarpas abruptas circundam os platôs e as áreas situadas entre os mesmos constituem vales densamente revestido pela floresta, com igarapés profundamente encaixados. Em alguns locais existem lagos onde o concrecionamento ferruginoso revestiu áreas rebaixadas ou irregulares da superfície de aplainamento, a maioria mantida pelas variações de pluviosidade invernal.

O clima em Carajás é tropical úmido nas áreas baixas revestidas pela floresta, mas nos platôs da Serra Norte há um período muito seco. A pluviosidade anual é elevada, com a média anual, em onze anos, de $2.236 \mathrm{~mm}$, variando de $382 \mathrm{~mm}$ em março, o mês mais chuvoso, a $26 \mathrm{~mm}$, em agosto, o mais seco (TOLBERT et al., 1971).

Os exemplares de peixe foram capturados na APA do igarapé Gelado, município de Parauapebas-PA, as espécies foram: piranhas (Serrasalmus spp.), branquinhas (Potamorhina spp.) e tucunarés (Cichla spp.), após a coleta realizada com o auxílio de barco e rede, os exemplares foram transportados sob refrigeração até o laboratório de patologia clínica do Instituto de Saúde e Produção Animal- ISPA na UFRA. Foi realizada a biometria e identificação taxonômica no laboratório de zoologia /UFRA utilizando-se parâmetros chaves de classificação. Para a análise dos metais retirou-se a parte dorsal da espécie triturou-se e efetuou-se a secagem em estufa a $40{ }^{\circ} \mathrm{C}$ por 48 horas.

Deve-se ressaltar que as análises dos peixes coletados referem-se apenas as partes comestíveis, pois o estudo teve como objetivo fornecer subsídios para análise do risco à saúde associada ao consumo dos peixes pela população. Os órgãos específicos (fígado, rim e outros), que acumulam mais intensamente metais tóxicos, não foram analisados. Estes órgãos devem ser considerados em futuras análises de risco ecológico e ambiental, já que são consumidos por outras espécies, tais como aves aquáticas.

Para a decomposição total do tecido dos peixes coletados foi utilizado o sistema de aquecimento por radiação de microondas DGT 100 da Provecto. Em cada reator foi pesada aproximadamente $0,20 \mathrm{~g}$ de amostra, em seguida foi feita a abertura utilizando três programas de dissolução, com combinações diferentes do reagente: ácido nítrico supra puro 65\% (Merck); ácido sulfúrico supra puro 98\% (Merck); peróxido de hidrogênio 32\% PA (Synth); ácido perclórico 70\% PA (Merck). As soluções resultantes deste procedimento foram então aferidas com água destilada em um balão volumétrico de $50 \mathrm{~mL}$ para posterior análise elementar. Toda água utilizada tinha resistividade mínima de $18,2 \mathrm{M} \Omega \mathrm{cm}^{-1}$ e foi fornecida pelo sistema de 
purificação Purelab Ultra Analytic da Elga, que usou água destilada como alimentação.

A análise dos metais foi realizada através do uso do ICPAES, modelo VistaPro, Varian. O princípio analítico do ICPAES é o mesmo de outros métodos espectroanalíticos onde diferentes elementos emitem e absorve radiação nos seus comprimentos de onda característicos, cuja energia absorvida ou emitida corresponde à diferença entre as camadas eletrônicas de seus átomos $\mathrm{O}$ aparelho foi calibrado para as análises com o uso de um padrão multielementar. Estas são soluções contendo todos os metais que se quer analisar, sendo necessário apenas diluir para as concentrações de interesse. As soluções são introduzidas por um sistema de bomba peristáltica em um atomizador de câmara ciclônica através de um nebulizador pneumático de tubo concêntrico, na qual a solução é convertida por um fluxo de gás comprimido em uma névoa de gotas finamente divididas, formando um aerossol, que é transportado até o plasma por um fluxo de argônio através do tubo central da tocha (SKOOG et al., 1998).

O controle de qualidade das determinações foi realizado através da análise de amostra de referência com certificado DORM-2 dogfish muscle certified reference material da National Research Council, onde elementos traço foram determinados em tecido de peixe. Os resultados demonstraram que o método adotado é adequado para a análise dos metais com boa exatidão (recuperações variando de 90,92 a 109,30\%) e boa precisão (coeficiente de variação para 10 replicatas variando de 4,25 a 12,53\%).

O método apresentou baixo limite de detecção e quantificação podendo ser aplicado a matrizes com níveis dos metais na faixa de partes por bilhão. O método foi linear para faixas de concentração variando de 0 a $5000 \mathrm{mg} / \mathrm{kg}$ para o $\mathrm{Al}, 0$ a 100 $\mathrm{mg} / \mathrm{kg}$ para o $\mathrm{Cd}$ e de 0 a $50 \mathrm{mg} / \mathrm{kg}$ para o $\mathrm{Cr}$ (Tabela 1 ).

Tabela 1 - Coeficiente de correlação, limite de detecção e de quantificação

\begin{tabular}{ccccc}
\hline Elemento & $\lambda(\mathbf{n m})$ & Coeficiente de Correlação & LD $(\mathbf{m g} / \mathbf{k g})$ & $\mathbf{L Q}(\mathbf{m g} / \mathbf{k g})$ \\
\hline $\mathrm{Al}$ & 237,31 & 0,9998 & 0,00207 & 0,00689 \\
$\mathrm{Cd}$ & 226,50 & 0,9996 & 0,00066 & 0,00220 \\
$\mathrm{Cr}$ & 276,65 & 0,9988 & 0,00087 & 0,00290 \\
\hline
\end{tabular}

LD = Limite de Detecção; LQ = Limite de Quantificação

\section{RESULTADOS E DISCUSSÃO}

$\mathrm{O}$ rio Gelado recebe diariamente elementos tóxicos como o $\mathrm{Cd}, \mathrm{Cr}$ e $\mathrm{Al}$, que são incorporados na biota e contaminam os indivíduos que consomem este alimento. Neste estudo $\mathrm{Al}, \mathrm{Cd}$ e $\mathrm{Cr}$ foram determinados em três espécies de peixe e os resultados estão mostrados na tabela 2 . 
$\mathrm{O}$ Al, em termos de média, foi encontrado em altas concentrações para todas as espécies avaliadas. O Brasil não possui legislação restritiva específica para o $\mathrm{Al}$ em peixes. Os valores encontrados para o Al estão muito acima aos encontrados por Turkmen et al., (2004) que encontraram concentrações em pescado variando de 0,02 a $5,41 \mathrm{mg} / \mathrm{kg}$ de peso seco. A seqüência para as espécies, em termos de enriquecimento do $\mathrm{Al}$, foi piranha $>$ branquinha $>$ tucunaré.

Embora o Al seja considerado um elemento essencial em elevadas concentrações esse metal pode acarretar, entre outros distúrbios, perda de memória e surgimento de demências como as provocadas pela doença de Alzheimer (ALLOWAY e AYRES, 1994).

Tabela 2 - Estatística descritiva dos resultados (mg/ $\mathrm{kg})$

\begin{tabular}{|c|c|c|c|c|c|}
\hline & Média & Mediana & Mínimo & Máximo & Desvio padrão \\
\hline \multicolumn{6}{|c|}{ Branquinha } \\
\hline Massa & 95,31 & 85,00 & 55,00 & 205,00 & 35,71 \\
\hline $\mathrm{Al}$ & 123,45 & 72,53 & 37,71 & 467,60 & 130,51 \\
\hline $\mathrm{Cd}$ & 1,87 & 2,16 & $<0,00220$ & 3,26 & 0,98 \\
\hline $\mathrm{Cr}$ & 1,75 & 0,99 & $<0,00087$ & 7,33 & 2,10 \\
\hline \multicolumn{6}{|c|}{ Piranha } \\
\hline Massa & 80,83 & 47,50 & 30,00 & 200,00 & 69,74 \\
\hline $\mathrm{Al}$ & 169,89 & 62,63 & 39,21 & 480,70 & 187,47 \\
\hline $\mathrm{Cd}$ & 1,84 & 1,74 & 1,24 & 2,85 & 0,59 \\
\hline $\mathrm{Cr}$ & 0,85 & 0,60 & $<0,00087$ & 1,95 & 0,93 \\
\hline \multicolumn{6}{|c|}{ Tucunaré } \\
\hline Massa & 383,33 & 300,00 & 300,00 & 550,00 & 144,34 \\
\hline $\mathrm{Al}$ & 46,07 & 45,29 & 45,24 & 47,67 & 1,39 \\
\hline $\mathrm{Cd}$ & 1,67 & 1,59 & 0,47 & 2,95 & 1,24 \\
\hline $\mathrm{Cr}$ & 1,45 & 1,06 & 0,40 & 2,88 & 1,28 \\
\hline
\end{tabular}

A presença do elemento no tecido das espécies avaliadas pode ter origem antrópica e natural já que o $\mathrm{Al}$ faz parte da geoquímica local e é um dos elementos mais abundantes na natureza. A disponibilidade do Al para os recursos hídricos amazônicos pode ser devido às características ácidas existentes na maioria dos igarapés locais que apresentam níveis elevados de ácidos húmicos e da lavagem do minério onde o elemento normalmente se encontra associado ao Fe (PEREIRA et al., 2007). Em pH baixo o Al existente nas rochas é solubilizado e pode, em altas 
concentrações, causar a mortandade de peixes por asfixia devido à formação de $\mathrm{Al}_{2}(\mathrm{OH})_{3}$ nas guelras dos peixes (BAIRD, 1999).

Para o Cd, a Portaria 685/98 da ANVISA (1998), estabelece $1,00 \mathrm{mg} / \mathrm{kg}$ como valor máximo permitido em pescado, neste estudo o $\mathrm{Cd}$ esteve em não conformidade com a legislação brasileira para todas as espécies analisadas. Para a branquinha a média encontrada está 1,87 vezes acima deste valor, na piranha está 1,84 vezes acima e no tucunaré está 1,67 vezes acima. A seqüência de enriquecimento para o $\mathrm{Cd}$ foi: branquinha $>$ piranha $>$ tucunaré.

Os valores encontrados neste trabalho para o Cd estão acima dos valores encontrados na literatura para este elemento em tecido de peixe. Meador et al. (2005) encontraram $\mathrm{Cd}$ em duas espécies de peixe variando de $<\mathrm{LD}$ a $0,3 \mathrm{mg} / \mathrm{kg}$ no Alasca e Califórnia. Alam et al. (2002) encontrou $0,009 \mathrm{mg} / \mathrm{kg}$ de Cd em carpa de um lago do Japão. Forero et al. (2009) encontraram Cd no músculo da espécie catfish (Eremophilus mutisii) em duas localidades do rio Bogotá (Chocontá $0,35 \mathrm{mg} / \mathrm{kg}$ e Suesca $0,48 \mathrm{mg} / \mathrm{kg}$ ) em concentrações abaixo dos valore encontrados neste estudo. Baixos resultados também foram encontrados por Turkmen et al. (2004).

Os valores encontrados para o $\mathrm{Cd}$ no músculo das espécies analisadas comprova a contaminação antrópica da biota do rio Gelado e mostra que a origem do elemento pode ser de fonte não natural já que o elemento não faz parte da geoquímica local. A presença de $\mathrm{Cd}$ em altas concentrações no pescado é preocupante, pois o $\mathrm{Cd}$ é um metal de elevado potencial tóxico, um irritante gastrointestinal, causando intoxicação aguda ou crônica sob a forma de sais solúveis (AARDT e ERDMANN, 2004). O Cd pode ser fator para vários processos patológicos no homem, incluindo disfunção renal, hipertensão, arteriosclerose, inibição no crescimento, doenças crônicas como a doença conhecida como Itai-itai e câncer (McELROY et al., 2006; OGAWA et al., 2004). O Cd se acumula em organismos avançados através de bioefeitos de ampliação na cadeia alimentar e podem entrar no corpo humano e se acumular nos tecidos e órgãos. Devido seu efeito bioacumulativo, mesmo em baixas concentrações é considerado danoso ao ser humano (QIAO-QIAO et al., 2007).

$\mathrm{O} \mathrm{Cr}$ apresentou altas concentrações em todas as espécies avaliadas, em relação ao máximo permitido $(0,1 \mathrm{mg} / \mathrm{kg})$ em pescado pela European Economic Community (EEC, 2001). Os valores encontrados neste trabalho para o Cr estão de acordo com os encontrados por Sivaperumal et al. (2007) e Forero et al. (2009) que encontraram Cr em altas concentrações variando de 1,8 a $2,1 \mathrm{mg} / \mathrm{kg}$ em rio que recebe efluente de curtume. A seqüência de enriquecimento para o $\mathrm{Cr}$ foi branquinha $>$ tucunaré> piranha.

A existência de $\mathrm{Cr}$ no tecido de peixes do rio Gelado é preocupante, pois existem muitas referências sobre os efeitos cancerígenos do $\mathrm{Cr}(\mathrm{VI})$, e outras sobre a possibilidade de íons $\mathrm{Cr}(\mathrm{V})$ também o serem; os íons Cr (III), entretanto, não parecem ter, diretamente, implicações tóxicas (LANGRRD, 2007). Segundo Cespón e Yebra (2009) o Cr é tanto um oligoelemento essencial como é tóxico. O Cr pode existir sob diferentes formas de oxidação. Os estados de oxidação mais importantes 
são III (estável, oligoelemento essencial) e VI (altamente tóxico, oxidante). $\mathrm{O} \mathrm{Cr}$ trivalente é o mais estável, e existe no sistema biológico. A forma hexavalente geralmente é de origem antropogênicas. No entanto, quando o $\mathrm{Cr}$ hexavalente é ingerido ele é eficiente reduzido para a forma trivalente no trato gastrointestinal.

Segundo Vutukuru (2005) a atividade respiratória normal dos peixes é significativamente afetada quando o animal é exposto ao $\mathrm{Cr}$ (VI). O metal também induz diminuição significativa $(\mathrm{p}<0,001)$ nos parâmetros hematológicos do peixe como contagem total de eritrócitos, a porcentagem de hemoglobina e o valor absoluto da hemoglobina celular média (HCM), ambos no final de 24 h e 96 h de exposição, indicando anemia. Também foi observada diminuição sensível nos perfis bioquímicos, como glicogênio total, lipídios totais e teores de proteína total dos peixes. A redução do teor de proteína foi significativa apenas no final de $96 \mathrm{~h}$. Este estudo reflete a extensão dos efeitos tóxicos do $\mathrm{Cr}$ hexavalente e o metal, induzindo os efeitos cumulativos prejudiciais a alterando vários níveis funcionais nos peixes de água doce que são amplamente consumidos.

No Box plot (Figura 2) observa-se a grande variabilidade do Al, enfatizando os valores médios das concentrações do elemento que confirma a estatística descritiva. $\mathrm{O} \mathrm{Al}$ apresentou quatro resultados extremos e nenhum resultado anômalo em todas as espécies avaliadas.

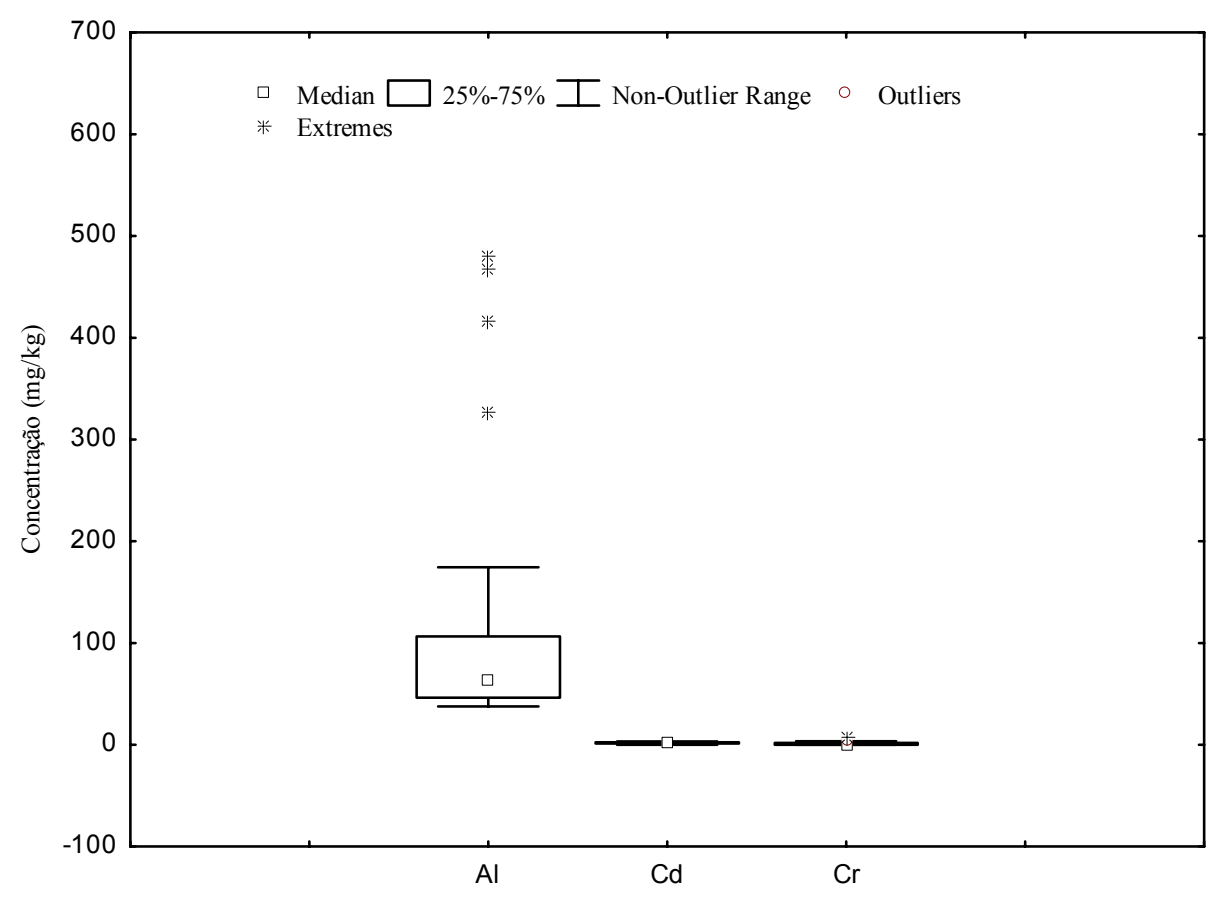

Figura 2. Box plot para os metais $\mathrm{Al}, \mathrm{Cd}$ e $\mathrm{Cr}$ nas amostras.

O Cd não apresentou resultados extremos e anômalos e o $\mathrm{Cr}$ apresentou um resultado extremo e um anômalo (outliers). Com o intuito de eliminar erros e validar as medidas analíticas, foi utilizado o teste de Dixon que é uma das formas estatísticas mais eficazes para eliminar erros experimentais por meio de uma medida escalar que 
indica se uma amostra pode ou não ser descartada do grupo amostral. Os resultados demonstram que nenhum resultado anômalo ou extremo pode ser descartado.

O estudo da correlação de Pearson demonstrou que existe excelente correlação positiva entre o $\mathrm{Al}$ e $\mathrm{Cr}$ na espécie piranha $(0,897)$ que comprova a similaridade de origem e comportamento metabólico dos dois elementos. No tucunaré foi observada uma boa correlação inversa para $\mathrm{Al}$ e $\mathrm{Cr}(-0,693)$ e também entre $\mathrm{Cd}$ e $\mathrm{Cr}(-0,668)$. A massa se correlacionou positivamente com o $\mathrm{Al}(1,000)$ e negativamente com o $\mathrm{Cr}$ (0,706) somente na espécie tucunaré. $\mathrm{Cd}$ e $\mathrm{Cr}$ se correlacionaram negativamente na branquinha $(-0,416)$. Cd e $\mathrm{Cr}$ não fazem parte da geoquímica local e podem ter origem antrópica.

As correlações entre os metais indicam a maneira que os metais são assimilados pela biota aquática e depende principalmente da similaridade entre os hábitos das espécies (TURKMEN et al., 2008). O sedimento contaminado pode ser uma importante fonte de metais para o ecossistema hídrico. Os peixes se contaminam pela ingestão de material particulado ou através da passagem da água contaminada pelas brânquias dos peixes (FORERO et al., 2009).

Com o objetivo de justificar os resultados estatísticos obtidos na análise de correlação bivariada foi realizado o teste de análise de bivariância (ANOVA) entre os elementos estudados. De acordo com os resultados não há diferença significativa entre os elementos, tomando como referência um valor de significância menor que 0,05 . Na correlação bivariada foi observada uma relação linear entre os elementos $\mathrm{Cr}$ e Al que apresentou um valor da correlação de Pearson de 0,897 na espécie piranha e uma significância de $0,015(<0,05)$, indicando que esta relação é significativa para o estudo.

\section{CONCLUSÃO}

$\mathrm{Na}$ APA do rio Gelado ficou comprovada a contaminação de piranha (Serrasalmus spp.), branquinha (Potamorhina spp.) e tucunaré (Cichla spp.) por Al, $\mathrm{Cd}$ e $\mathrm{Cr}$ em altas concentrações. Os resultados são preocupantes principalmente em relação ao $\mathrm{Cd}$ elemento altamente tóxico, bioacumulativo e cancerígeno e $\mathrm{Cr}$ na forma hexavalente também tóxico e cancerígeno. A população que consome este pescado pode ser afetada pelos problemas de saúde associados aos elementos.

A análise estatística dos dados obtidos revela através do estudo da correlação entre os metais estudados, que a origem dos elementos nos peixes avaliados pode ter origem geoquímica adicionados ao meio ambiente hídrico através da lixiviação e ou solubilização do solo, quanto de origem antrópica pelas atividades de mineração na área. Outros estudos devem ser realizados visando explicar a dinâmica de interrelação destes metais nesta região. 


\section{AGRADECIMENTOS}

Os autores gostariam de agradecer ao Laboratório Central da Eletronorte, aos Msc. Químicos Augusto Saraiva e Maurício A. Lima pelo auxílio na análise das amostras.

\section{REFERÊNCIAS}

ALAM, M.G.M.; TANAKA, A.; ALLINSON, G.; LAURENSON, L.J.B.;

STAGNITTI, F.; SNOW, E.T. A comparison of trace element concentrations in cultured and wild carp (Cyprinus carpio) of Lake Kasumigaura, Japan.

Ecotoxicology and Environmental Safety, v.53, p.348-354, 2002.

ANVISA - AGÊNCIA NACIONAL DE VIGILÂNCIA SANITÁRIA. Portaria $\mathrm{n}^{\circ}$ 685, de 27 de agosto de 1998. Disponível em: < http://www.anvisa.gov.br/e-legis/>. Acesso em: 15 de Jan de 2009.

AARDT, W.J.; ERDMANN, R. Heavy metals $(\mathrm{Cd}, \mathrm{Pb}, \mathrm{Cu}, \mathrm{Zn})$ in mudfish and sediments from three hard-water dams of the Mooi River catchment, South Africa. Water SA, v.30, n.2, p. 211-215, 2004.

ALLOWAY, B. J.; AYRES, D. C. Chemical principles of environmental pollution. Londres: Blackie A \& P, 1994. 304 p.

ATCHISON, G.H; HENERY, M.G.; SANDHEINRICH, M.B. Effect of metals on fish behavior: a review. Environmental Biology Fish, v.18, p.11-25, 1987.

AVEGLIANO, R. P.; MAIHARA, V. A.; SILVA, F. F. Metodologia de estudo de dieta total no estado de São Paulo para estimativa de ingestão dietética de elementos tóxicos e essenciais: a elaboração da cesta de mercado (Market Basket). Ciência e Tecnologia de Alimententos, v. 28, v.1, p. 90-97, 2008.

BAIRD, C. Environmental Chemistry. $2^{\text {a }}$ ed. University of Western Ontario. 1999, $557 \mathrm{p}$.

BECKER, B.; MACHADO, L. Uma Nova Fronteira para o Século XXI. Ciência Hoje, v.1, n.3, p.45-46, 1982.

BURGER, J.; COCHFELD, M. On developing bioindicators for human and ecological health. Environmental Monitoring and Assessment, v. 66, p.23-46, 2001. 
CARRINO, T. A.; SOUZA FILHO, C. R.; LEITE, E. P. Processamento e integração de imagens multiespectrais, de radar e aerogeofísicas do bloco Serra Leste (Carajás, PA) e discussão do potencial para mineralização de ferro. Revista Brasileira de Geofísica, v.26, v.2, p. 123-140, 2008.

CESPÓN, R. M.; YEBRA, M. C. Flow injection determination of total chromium in urine of occupationally exposed workers. Microchimica Acta, v.164, v.1-2, p.225229, 2009.

EEC - EUROPEAN ECONOMIC COMMUNITY - Regolamento n ${ }^{\circ} 466 / 2001$ della

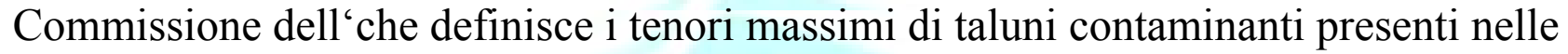
derrate alimentary. Gazzetta Ufficiale delle Comunita' Europee, L77 16 March, 2001 .

FORAN, J. A. Toxic substances in surface waters. Environmental Science Technology, v. 24, n.15, p.604-608, 1990.

FORERO, A. R.; MANTILLA, J. F. G.; MARTÍN, R. S. Accumulation of Lead, Chromium, and Cadmium in Muscle of capitán (Eremophilus mutisii), a Catfish from the Bogota River Basin. Archives of Environmental Contamination and Toxicology, v.57, n.2, p.359-365, 2009.

GOLDBERG, E. D.; KOYDE, M; HODGE, V.; FLEGAL, A. R.; MARTIN, J.U.S. Mussel Watch 1977-1978: Results on trace metals and radio nuclides. Estuarine Coastal and Shelf Science, v. 16, p. 69-83. 1983.

JONES, G. B.; MERCURIO, P.; OLIVIER, F. Zinc in Fish, Crabs, Oysters, and mangrove flora and fauna from Cleveland bay. Marine Pollution Bulletin, v. 41, n.7-12, p.345-352, 2000.

LANGRRD, S. One hundred years of chromium and cancer: A review of epidemiological evidence and selected case reports. American Journal of Industrial Medicine, v.17, n.2, p. 189-214, 2007.

LEWIS, M. A.; SCOTT, G. I.; BEARDEN, D. W.; QUARLES, R. L.; MOORE, J.; STROZIER, E. D.; SIVERTSEN, S. K.; DIAS, A. R.; SANDERS, M. F. Tissue quality in near-coastal areas of the Gulf of Mexico receiving point source discharges. The Science of the Total Environment, v. 284, n.1-3, p.249-261, 2002.

MACKAY, D; CLARK, K.E. Predicting the environmental partitioning of organic contaminants and their transfer to biota. In: Jones, K.C. Organic 
Contaminants in the environment. Environmental Management Series, Elsevier Science Pub, New York, 1991, 254p.

McELROY, J. A.; SHAFER, M. M.; TRENTHAM-DIETZ, A.; HAMPTON, J. M.; NEWCOMB, P. A. Cadmium Exposure and Breast Cancer Risk. Journal of the National Cancer Institute, v. 98, n.12, p.869-873, 2006.

MEADOR, J. P.; ERNEST, D. W.; KAGLEY, A. N. A comparison of the nonessential elements cadmium, mercury, and lead found in fish and sediment from Alaska and California. Science of the Total Environment, v. 339, p.189-205, 2005.

NIENCHESKI, L. F.; WINDOM, H. L.; BARAJ, B.; WELLS, D.; SMITH, R. Mercury in fish from Patos and Mirim lagoons, Southern Brazil. Marine Pollution Bulletin, v. 42, p. 1403-1406, 2001

OGAWA, T.; KOBAYASHI, E.; OKUBO, Y.; SUWAZONO, Y.; KIDO, T.; NOGAWA, K. Relationship among prevalence of patients with Itai-itai disease, prevalence of abnormal urinary findings, and cadmium concentrations in rice of individual hamlets in the Jinzu River basin, Toyama prefecture of Japan.

International Journal of Environmental Health Research, v.14, n.4, p.243-252, 2004.

PEREIRA, S.F.P.; LIMA, M. A.; FREITAS, K. H.; MESCOUTO, C. S.; SARAIVA, A. F. Estudo químico ambiental do rio Murucupi - Barcarena/PA, área impactada pela produção de alumínio. Revista Ambiente e Água - An interdisciplinary Journal of Applied Science, v.2, n.3, p. 62-82, 2007.

QIAO-QIAO, C.; GUANG-WEI, Z.; LANGDON, A. Bioaccumulation of heavy metals in fishes from Taihu Lake, China. Journal of Environmental Sciences, v.19, n.1500-1504, 2007.

SIVAPERUMAL, P.; SANKAR, T. V.; NAIR, P.G.V. Heavy metal concentrations in fish, shellfish and fish products from internal markets of India vis-à-vis international standards. Food Chemistry, v. 102, p. 612-620, 2007.

SKOOG, D.A.; HOLLER, F.J.; NIEMAN, T.A. Principles of instrumental analysis. $5^{\text {a }}$ ed. Florida. Ed. Saunders college publishing. p. 849, 1998.

STEIN, J. E.; COLLIER, T. K.; REICHERT, W. L.; CASILLAS, E.; HOM, T.; VARANASI, U. Bioindicators of contaminant exposure and sublethal effects: studies with benthic fish in puget sound, Washington. Environmental Toxicology and Chemistry, v.11, n.5, p.701-714, 1992. 
TOLBERT, G. E.; TREMAINE, J. W.; MELCHER, G. C.; GOMES, C. B. The recently discovered Serra dos Carajás iron deposits, northern Brazil. Economic Geology, v. 66, n.7, p. 985-994, 1971.

TRIEBSKORN, R.; TELCEAN, I.; CASPER, H.; FARKAS, A.; SANDU, C.; STAN, G.; COLĂRESCU, O.; DORI, T.; KÖHLER, H. R. Monitoring pollution in River Mureş, Romania, part II: Metal accumulation and histopathology in fish.

Environmental Monitoring and Assessment, v.41, n.1-3, p.177-188, 2008.

TURKMEN, A.; TURKMEN, M.; TEPE, Y.; AKYURT, I. Heavy metals in three commercially valuable fish species from Iskenderun Bay, Northern East Mediterranean Sea, Turkey. Food Chemistry, v. 91, n.1, p.167-172, 2004.

TURKMEN, M.; TURKMEN, A.; TEPE, Y. Metal contaminations in five fish species from Black, Marmara, Aegean and Mediterranean Seas, Turkey. Journal of the Chilean Chemical Society, v.53, n.1, p.1424-1428, 2008.

TÜZEN, M. Determination of heavy metals in fish samples of the middle Black Sea (Turkey) by graphite furnace atomic absorption spectrometry. Food chemistry, v.80, p. 119-123, 2003.

VUTUKURU, S. S. Acute Effects of Hexavalent Chromium on Survival, Oxygen Consumption, Hematological Parameters and Some Biochemical Profiles of the Indian Major Carp, Labeo rohita. International Journal of Environmental Research Public Health, v.2, n.3, p. 456-462, 2005.

WOO, P.T.K. (Ed.). Fish Diseases and Disorders. Protozoan and Metazoan Infections. vol. I. CAB International. Oxon. 808 p. 1995. 